\title{
REFLEXÓES SOBRE MITOS NO MANUSCRITO AUTOBIOGRÁFICO DE HERCULINE BARBIN
}

\author{
Sarug Dagir Ribeiro* \\ Universidade Federal de Minas Gerais
}

\begin{abstract}
This paper aims at presenting a reflection on a manuscript of autobiographical nature left by Abel/Adelaide Herculine Barbin, someone with a hermaphroditic condition who was born in 1838 and committed suicide at the age of thirty. Following the trail of Barbin's text, we will consider its influence as an autobiographical document in which literary and mythical representations are present and preserved. This undertaking is an attempt to conduct a dialogue between myths and text (Barbin's manuscript).
\end{abstract}

KEYWORDS: autobiography; Herculine Barbin; hermaphrodite; myth.

\section{Introdução}

$6 \mathrm{~m}$ povos bastante primitivos, a ideia de um ser hermafroditos está ligada aos poderes de uma divindade que domina a vida e a morte. Mircea Eliade, estudando as religiões da Mesopotâmia, esclarece-nos que, "[n]o seu apogeu, Inanna-Ishtar era ao mesmo tempo deusa do amor e da guerra, isto é, regia a vida e a morte; para indicar a plenitude dos seus poderes, dizia-se que ela era hermafrodita (Ishtarbarbata)". ${ }^{1}$ De Hermafrodito, uma divindade da Grécia antiga à qual se prestavam cultos

\footnotetext{
^sdagir@gmail.com

${ }^{1}$ Cf. Eliade, M. História das crenças e das ideias religiosas. Tomo I: da Idade da Pedra aos Mistérios de Elêusis. Vol. I: das Origens ao Judaísmo. 2. ed. Rio de Janeiro: Jorge Zahar, 1983, p. 87.
} 
e oferendas desde o quarto século antes de Cristo, testemunham textos antigos como os Caracteres $(16,10)$ de Teofrasto (370-288 a.C.) e o Diálogo dos Deuses $(3,23 ; 17,15)$ de Luciano (120-190 d.C.). Entretanto, se já havia uma positivação dessa divindade na época clássica e helenística, Hermafrodito chegou, como veremos à frente, a ser comparado a Zeus, o deus supremo para os gregos. Curiosamente, a mesma categoria tornou-se, no século XIX, um monstro na cultura ocidental.

Conjuguemos Antiguidade e o século XIX. Neste sentido, e a fim de prosseguirmos com nosso estudo, recorramos a Foucault - o descobridor e prefaciador do diário de Abel/ Adelaide Herculine Barbin e para quem observar o hermafroditos, entre outros fatos e mitos, propiciou construir um discurso científico sobre a sexualidade -, que define o monstro "como um fenômeno ao mesmo tempo extremo e extremamente raro. Ele é o limite, o ponto de inflexão da lei (...) é o que combina o impossível com o proibido". ${ }^{2}$ Dessa forma, segundo o pensador francês, o monstro está situado no domínio "jurídico-biológico". Nesse artigo teremos como principal objetivo apontar como, no texto autobiográfico de Herculine Barbin, relaciona-se a figura mítica do hermafroditos da Antiguidade clássica com o monstro moderno do século XIX.

\section{O diário de Herculine Barbin}

A morte de Herculine Barbin, rodeada pelo imaginário social e moral de sua época que a viu como monstro, no nosso ponto de vista, foi fruto de grande pressão social e emocional o que acabou por levá-la à sua própria destruição pelo suicídio. Vale lembrar que, por volta dos anos de 1860-1870, a procura da identidade na ordem sexual é praticada, cada vez mais, com maior ferocidade pela medicina e pela justiça, impondo uma norma rígida na definição e na captura do verdadeiro sexo para os indivíduos de condição hermafrodita. Essa postura jurídicobiológica se manteve feroz e constante, exercendo influências até os dias de hoje, quando é usual que um indivíduo hermafrodita seja submetido, ao nascer, a ininterruptas cirurgias corretivas para estabelecimento definitivo de sua genitália.

Herculine Barbin, no seu manuscrito autobiográfico, resgata da Antiguidade o mito do hermafroditos como uma tentativa de recuperação

${ }^{2}$ Cf. Foucault, M. Os anormais. Curso no Collège de France (1974-1975). São Paulo: Martins Fontes, 2001, p. 70. 
da sua dignidade. Ao ponderar que "[o] que ela [Herculine] evoca do seu passado é o limbo feliz de uma não-identidade", 3 Foucault explicitamente condiciona a felicidade de Herculine Barbin à sua condição hermafrodita em uma cultura que, à época, não oferecia alternativas satisfatórias. As propostas sociais em prática eram de exclusão (banimento, exílio, apagamento...) ou de proibição (correção, cura, monstrificação...). Diante de uma resposta insatisfatória, Herculine Barbin buscou nos mitos uma inteligibilidade de sua situação sexual. Os mitos oscilam da positivação à negativização. Mas o ponto comum é a inserção na contranatureza; vejamos:

Minha natureza angelical, paira por sobre todas as vossas inomináveis misérias (...) A vós a terra, a mim o espaço sem limites. (...) Oh, quem poderia julgar os impulsos de pura embriaguez de uma alma que nada tem de terrestre e humano?! (...) Sim, lastimo por vós por que não sofrestes. Para sofrer é preciso ter um coração nobre, grande, e uma alma generosa. ${ }^{4}$

Confesso que fiquei particularmente transtornada com a leitura das Metamorfoses de Ovídio. Quem as conhece pode ter uma ideia do que significam. Esse achado tinha para mim uma singularidade que a continuação de minha história provará. (...) O verdadeiro, por mais exorbitante que seja, não ultrapassa às vezes todas as concepções do ideal? As metamorfoses de Ovídio não estariam próximas disso?

O autor que Barbin cita é Públio Ovídio Nasão (43 a.C. - 17 d.C.), poeta que escreveu As Metamorfoses e que é considerado um mestre da poesia latina, tendo influenciado diversas gerações de artistas como Dante, Shakespeare e Milton. Nasceu, de família abastada, em Sulmo, atual Sulmona, na Itália, no ano de 43 a.C.. Enviado a Roma para estudar retórica, dedicou-se à poesia e conviveu com Horácio e Propércio, integrando o círculo de Mecenas. É autor de obras como Amores, Ars amatoria, Epistulae Heroidum, Remedia amoris. No auge do prestígio, foi acusado de imoralidade pelo imperador Augusto e condenado ao exílio; então compôs duas obras magistrais: Tristia e Epistulae ex Ponto. Morreu na Dácia. Contudo, as Metamorfoses, produzidas já em sua maturidade,

\footnotetext{
${ }^{3}$ Cf. Foucault, M. Herculine Barbin. O diário de um hermafrodita. Rio de Janeiro: Francisco Alves, 1982, p. 7.

${ }^{4}$ Cf. Foucault, op. cit., 1982, p. 93.

${ }^{5}$ Cf. Foucault, op. cit., 1982, p. 26 e 83.
} 
constituem o maior interesse para Herculine Barbin, que se refere à peça pelo menos duas vezes em sua autobiografia. A obra foi escrita aproximadamente entre os anos 2 e 8 da era cristã. Trata-se de um poema de natureza narrativa composto em quinze livros redigido em versos hexâmetros. Seu conteúdo se refere a um conjunto de lendas, de origem helênica, cada uma das quais narrando uma metamorfose. Estas histórias estão dispostas em ordem cronológica, sendo a história antecedente relacionada com a que se segue. Constrói-se, assim, um enorme afresco mítico, que abarca desde a criação do mundo até a divinização de Júlio César, terminando com uma homenagem a Augusto. Considerada a complexidade e enormidade da obra, focalizaremos nossa atenção no livro IV, na parte aqui nomeada de "Salmácida, Hermafrodita":

Um menino filho de Mercúrio e da deusa Citereia foi criado pelas náiades nas grutas do Ida; seus traços fisionômicos permitiam reconhecer quem era o pai e quem era a mãe; também o seu nome foi tirado de ambos. Quando completou três lustros, abandonou as montanhas pátrias, e saindo de onde se criara, alegrou-se em viajar por lugares desconhecidos, ver rios desconhecidos, e a curiosidade aliviava o cansaço. Visitou também as cidades lícias e os caios, vizinhos da Lícia. Ali viu um lago cuja água é transparente até o fundo. Não crescem ali nem cálamos palustres, nem ervas daninhas, nem juncos de ponta afiada (...). (...) Uma ninfa mora ali, mas não se dedica à caça (...). Muitas vezes, colhe flores. Estava colhendo-as, por acaso, quando viu o adolescente, e, vendo-o, desejou conquistá-lo. (...) (A)garra o jovem que resiste, rouba-lhe beijos enquanto luta, abraça-o, acaricialhe o peito contra a sua vontade, e ele se vê envolvido, ora de um lado, ora de outro. (...) Resiste o descendente de Atlas e nega à ninfa o prazer que ela espera. Ela o retém com mais força, e com todo o corpo unido ao dele, pareciam pregados um ao outro. Podes lutar, perverso, mas não fugirás, disse. Ordenai, ó deuses, que jamais ele possa se separar de mim ou eu dele! Os deuses ouviram sua súplica. Eis que os corpos dos dois foram juntados intimamente e se tornam um só corpo. (...) (D)epois que os membros dos dois se uniram em um forte amplexo, já não são dois, mas têm uma dupla forma, não se pode dizer que seja uma mulher ou um adolescente, o aspecto não é nem de um nem de outro, e é, ao mesmo tempo, de um e outro. ${ }^{6}$

${ }^{6}$ Ovídio, Metamorfoses, 1983, p. 75-76 (no original latino, o relato corresponde a IV 285-388). 
Desde as Metamorfoses de Ovídio, passando por Balzac, em Sarrazine, e por Virginia Woolf, em Orlando, o hermafroditismo é presença habitual no mundo mítico, poético e romanesco da humanidade. Para um maior esclarecimento do tema, realizamos a seguir uma breve nota sobre as semelhanças e as diferenças entre o hermafroditos e o andróginos.

\section{Mitologia greco-latina: semelhanças e diferenças entre o hermafroditos e o andróginos}

Há diversos processos de produção sígnica que mimetizam múltiplos registros de construção de imagens em diferentes concepções e experimentações do tempo e da memória. As narrativas míticas foram predominantemente orais e geralmente descreviam uma determinada forma de conceber e explicar o mundo. Um mito sofre diversas transformações até chegar à produção literária, textual e, mesmo assim, continua a sofrer constantes e frequentes transformações e adaptações. É o que acontece, por exemplo, com a lenda judaica do Golem, cuja versão literária mais famosa é atribuída a Gustav Meyrink.

Dessa mesma forma podemos pensar sobre o processo de construção em torno da imagem do hermafroditos. Pinturas, esculturas, textos e objetos de usos diversos, como afirmamos, revelam que a Antiguidade considerava o hermafroditos um deus, um ser supremo. Seu primeiro aparecimento na literatura grega (tomando como fonte apenas os textos legados pela história), nas fontes epigráficas e nas iconográficas, data do quarto século a.C.. As fontes literárias são abundantes, citamolas apud Aileen Ajootiam no Lexicon Iconographicum Mythologiae Classicae: Teofrasto em Caracteres (16, 10); Plínio em Natura (36, 33); Luciano de Samósata em Diálogo dos deuses $(3,1 ; 17,2)$; Tito Lucrécio Caro em De rerum Natura (V, 835-840). ${ }^{7}$ No entanto, a discussão mais conhecida é a de Ovídio nas Metamorfoses, na qual o autor apresenta a ninfa Sálmacis como sendo aquela responsável pela fusão de sexos do jovem filho de Hermes e Afrodite. Contudo, o hermafroditos não foi somente uma criatura bissexual na tradição mitológica grega. $\mathrm{Na}$ cosmologia órfica, ele é chamado de "Phanes", "Protogonos", "Bromios", "Zeus", e "Eros".

\footnotetext{
${ }^{7}$ As referências aos autores antigos são tomadas do LIMC (Lexicon Iconographicum Mythologiae Classicae) Zurich: Artemis Verlag Zurich und München, 1981. Vol. V, 1.

${ }^{8}$ Cf. Brisson, L. Sexual ambivalence. Androgyny and hermaphroditism in Graeco-Roman Antiquity. Berkeley/ Los Angeles: University of California Press, 2002, p. 94-95.
} 
Outros nomes que lhes são alternativos: Atlântides e Andróginos. Como vimos, há evidências de culto à sua imagem. Teofrasto registra a existência de dias determinados para se lhe fazerem oferendas, ${ }^{9}$ cujos objetos, ainda preservados, podem ser encontrados na Itália, Áustria, França, Inglaterra, Grécia, Chipre, Ásia Menor e Norte da África, representados por esculturas em relevo em mármore, desenhos, mosaicos e pinturas. A mais antiga imagem de um hermafroditos de que temos notícia é referida por Plínio em Natura, nos versos 34 e 80, trecho no qual o autor faz referência a uma escultura de bronze intitulada Hermaphroditus nobilis, trabalho atribuído a Pólicles, artista que teria vivido entre 372 e 369 a.C. De acordo com as evidências literárias e iconográficas, as imagens do hermafroditos geralmente vêm marcadas com um falo ereto, como característica da descendência de sua linhagem, pois são seus irmãos Eros e Priapo e Hermes é seu pai. À sua família ajuntam-se Baubo, Ísis e Átis, divindades e seres mitológicos apresentados de forma similar. Essas imagens serviram para indicar lugares como ginásios, templos, saunas, teatros e até casas.

Em relação ao aspecto fisiológico, o andróginos e o hermafroditos são formalmente idênticos, conforme Junito de Souza Brandão afirma no Dicionário mítico-etimológico da mitologia grega:

(...) enquanto reunidos, enlaçados, ambos são estéreis, porque são simbióticos. Mas, é exatamente aí que reside a grande diferença entre os dois pares: o hermafroditos jamais poderia ser dividido, desagregado, separado, este foi o pedido de Sálmacis aos deuses, que the atenderam a súplica. E mesmo que o fosse, sexualmente falando, não haveria fecundação, uma vez que Hermafroditos sofre de impotentia coeundiet generandi, uma impotência para o coito e para a fecundação. ${ }^{10}$

Para Brandão o pedido de hermafroditos dirigido a seus pais, de que todo aquele que se banhasse nas águas de Sálmacis permanecesse estéril significa também sua própria condição de impotente. No que se refere ao andróginos, porém, isso é inteiramente diverso, visto que a sexualidade, a capacidade de copulação e de fecundação está latente. "Bastou que Zeus", como escreve Platão, "os separasse, para que cada uma das metades, tornando-se carente, se pusesse a buscar a outra

${ }^{9}$ Cf. Théophraste. Charactères. Texte établie et traduit par Octave Navarre. Paris: Les Belles Lettres, 1964, cap. XVI, 10.

${ }^{10}$ Cf. Brandão, J. S. Dicionário mítico-etimológico da mitologia grega. Petrópolis: Vozes, 1993, p. 547. 
contrária, numa ânsia e num desejo insopitáveis de se 're-unir' para sempre". ${ }^{11}$ Dito isso, podemos concluir, juntamente com Brandão, que no andróginos há um movimento de um para dois, dada sua separação; já no hermafroditos não há movimento, mas paralisia de dois para um, dada sua inseparabilidade.

Depois dessa explicação, realizada no intuito do esclarecimento das nuanças atinentes à temática colocada, voltemos à análise do texto de Herculine Barbin. Northrop Frye observa que,

Em termos de narração, o mito é a imitação das ações que raiam pelos limites concebíveis do desejo, ou que se situam nesses limites. $\mathrm{O}$ fato de o mito operar no plano mais alto do desejo humano não significa que apresente necessariamente seu mundo como atingido ou atingível por seres humanos. O mito, portanto, é um extremo da invenção literária. Na crítica literária o mito é normalmente a chave metafórica das deslocações da estória romanesca. ${ }^{12}$

Nessa direção, pode-se propor que a escrita de Barbin é sofisticada porquanto se mostra rica em recursos metafóricos, cuja operação da letra é calcada na mitologia, não só greco-latina, como também hebraica; aqui, "a mitologia é um domínio parcelar da investigação geral sobre a narrativa". ${ }^{13}$

\section{Figuras míticas: o anjo}

$\mathrm{Na}$ Bíblia encontramos diversas ocorrências de anjos que dão força aos homens. Por exemplo, tomemos o livro I de Reis, no Velho Testamento, no qual o profeta Elias foge para o deserto por causa da cólera de Jezebel. Estando cansado e assustado, pede a Deus para matálo. No entanto, quando adormece, um anjo acorda-o por duas vezes a fim de que comesse e bebesse o bolo e a água que lhe havia trazido, fazendo com que Elias se revigorasse por esse alimento. E é também dessa forma que Barbin se expressa em sua escrita: "Como uma visão celeste, surgiu em meus descaminhos, dando-me força e consolação!" ${ }^{14}$ Não seria uma solução para Herculine Barbin, dentro do universo mítico,

\footnotetext{
${ }^{11}$ Cf. Brandão, op. cit., p. 547.

${ }^{12}$ Cf. Frye, N. Anatomia da crítica. São Paulo: Cultrix, 1957, p. 138-187.

${ }^{13}$ Cf. Burkert, W. Mito e mitologia. Coimbra: Faculdade de Letras, 1986, p. 4.

${ }^{14}$ Cf. Foucault, op. cit. 1982, p. 34-35.
} 
admitir-se com uma força extra-humana e de uma natureza angelical? "Quanto mais a crise se aproximava, mais eu sentia aumentar minhas forças!" "São inúmeros os exemplos, na literatura, da referência a anjos: Camões, em Os Lusíadas; Sophy Burnham, em The book of angels; Ken Carey, em $O$ retorno das tribos-pássaro, Transmissões da estrela-semente: Gitta Mallasz, em Talking with angels; o poeta Rainer Maria Rilke; Dante Alighieri, em Divina Comédia; John Milton em seus épicos Paraíso perdido e Paraíso reconquistado; Ibn Arabi em The Meccan revelations. Mas estamos longe de querer abranger um possível universal mítico. Essa listagem é despretensiosa e pretende apenas mostrar com que facilidade se enumeram ocorrências para esse caso. E, assim, se em muitas fontes literárias tradicionais os anjos nos alimentam, confortam e fortalecem para enfrentar crises, Herculine Barbin, semelhantemente, assume-se como tal, mantendose na categoria dos "anormais" de Foucault, mas no sentido de positivála. Antes, entretanto, de propriamente pontuarmos Herculine Barbin nomeando-se como um ser angelical, observemos em seu relato passagens com menção a esse universo mítico ou a uma natureza angelical identificada, vez ou outra, em amigas e companheiras:

Sua lembrança é ainda uma das mais doces que me restou. Em meio às inacreditáveis agitações da minha vida, eu gostava de lembrar a suavidade daquele sorriso de anjo, e me sentia mais feliz.

Seria dizer que todas as suposições feitas a respeito de minhas relações anteriores com aqueles anjos terrestres são falsas, inteiramente falsas. (...) Devo obviamente à solidez dos princípios de minha juventude, que eram extremamente puros, o fato de não ter do que me envergonhar diante daqueles rostos cândidos, cuja serenidade não foi perturbada por mim. ${ }^{16}$

É salutar observar que Herculine Barbin adquiria força diante da adversidade e do perigo comportando-se como um ser angelical, ou seja, utilizando-se do "princípio da inteligibilidade" teorizado por Foucault:

Diante do perigo, entretanto, sinto-me forte. A infelicidade me enche de coragem. E foi assim que me senti naquele instante, em que estava em jogo toda a minha vida... A guerra que provavelmente ia ter que enfrentar, me dava um impulso sobrenatural. ${ }^{17}$

${ }^{15}$ Cf. Foucault, op. cit. 1982 , p. 64.

${ }^{16}$ Cf. Foucault, op. cit. 1982, p. 17 e 89.

${ }^{17}$ Cf. Foucault, op. cit. 1982, p. 74. 
Apontemos finalmente a passagem em que se autodetermina um anjo:

Minha natureza angelical, paira por sobre todas as vossas inomináveis misérias, pois me dissestes que não há lugar para mim em vossa estreita esfera. A vós a terra, a mim o espaço sem limites. Acorrentados pelos laços dos vossos sentidos grosseiros, vossos espíritos não podem mergulhar no límpido mar do infinito, onde minha alma em desvario por sobre vossas praias áridas, sacia a sua sede. Arrancada por antecipação de seu corpo virgem, entreviu com beatitude a luminosa claridade de um mundo imortal, resplandecente, onde sua permanência futura é desejada. Oh, quem poderia julgar os impulsos de pura embriaguez de uma alma que nada tem de terrestre e humano?! (...) eu não pertencia a ninguém... a não ser a Deus. ${ }^{18}$

Logo em seguida, Herculine aponta para o martírio como condição da sua beatitude:

Sou eu quem deveria me queixar, pobres espíritos pecadores, que consumiram em miseráveis prazeres todas as fontes vivas de seus corações, que apagaram da inteligência a chama pura, destinada a guiar sua razão nos caminhos da vida. E então ficareis apavorados com o vazio medonho de vosso ser. ${ }^{19}$

Fomos, portanto, conduzidos, no diário de Barbin, entre categorias: anjo e monstro, entre o masculino e o feminino e, procurando relacionar os fatos de sua vida hermafrodita à singularidade de sua escrita, constatamos que há um estilo alusivo à sua peculiar condição, numa narrativa que escapa às capturas de uma possível identificação do sexo. Constatamos que é difícil manter o jogo de epítetos ora masculinos ora femininos aplicados com abundância pelo narrador para se definir. $O$ traço marcante de seu texto é justamente essa não-identidade sexual. É dessa hesitação que provém a singularidade que marca o texto de Herculine Barbin, que transforma o mais subjetivo dos sofrimentos em textualidade de qualidade literária, poética e - por que não dizer? mítica também.

Parte de seu trabalho de ficcionalização é assumido na recorrência aos mitos, criando um curioso efeito: apartada de qualquer realidade, sua história é compreendida a partir do não-ser, ou quem sabe, do seralém. A estratégia de apoiar-se em personagens míticos leva seu relato

\footnotetext{
${ }^{18}$ Cf. Foucault, op. cit. 1982, p. 93 e 94.

${ }^{19}$ Cf. Foucault, op. cit. 1982, p. 93.
} 
a uma abrangência mais universal. O uso da mitologia clássica, como teorizou Foucault no "princípio de inteligibilidade", foi elemento auxiliar e disciplinador de seus esforços para reconstruir e inventar sua história de vida. A mitologia aparece, destarte, como elemento estruturador de um trabalho organizacional da memória de experiências vividas. Dessa maneira, seu manuscrito presta-se ao debate a respeito dos limites entre a autobiografia e a ficção, esta última entendida como mitificação, pois põe em xeque o estabelecimento dessas diferenças, ou seja, o "eu" como entidade textual e sua ficcionalidade. Fantasia e realidade são aspectos intercambiáveis e inerentes à vida psíquica. A escrita de Herculine Barbin faz justamente essa transformação, na qual experiência vivida e memória não coincidem.

Finalizamos esse artigo com as belas palavras de Herculine Barbin: "Nasci para amar. Todas as faculdades de minha alma estavam voltadas para o amor." ${ }^{20}$ Não seriam essas palavras muito semelhantes às de

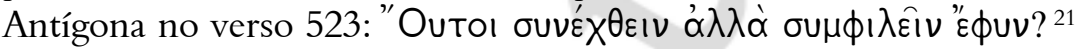

De todas as pontuações aqui arroladas, nada nos autoriza a uma associação direta. Sugerimos apenas associações poéticas por uma possível intertextualidade. A condição de Herculine Barbin, assim como a de Antígona, pode ser analisada sob o aspecto não menos importante do conflito entre a lei do Estado e a liberdade individual. Para o lado de Barbin, temos a ditadura de uma inevitável escolha de um único sexo, o verdadeiro, o que a priva da liberdade de indefinição; para o lado de Antígona, teremos a lei estatal de seu tio Creonte, que pró́be, sob pena de morte, que se prestem ritos fúnebres ao corpo de Polínices, seu irmão, contra as leis divinas, às quais Antígona presta obediência. A morte de Herculine Barbin, assim como a morte de Antígona, dá lugar a um debate político. Ambos são suicídios como uma ação política, uma denúncia. Tanto o heroísmo de Barbin quanto o de Antígona foram considerados perigo público, o que lhes trouxe, cada uma à sua maneira, amarga solidão. Ambas desarranjaram a ordem estabelecida, opuseram resistência à razão de Estado. São notórios signos de transgressão, coragem e solidão.

${ }^{20}$ Cf. Foucault, op. cit. 1982, p. 33.

${ }^{21}$ Sófocles, Antígona, v. 523: Não nasci para odiar, mas sim para amar (tradução de Maria Helena da Rocha Pereira). 


\section{Referências}

ALBERTI, V. Literatura e autobiografia. A questão do sujeito na narrativa. Rio de Janeiro: Editora da Fundação Getúlio Vargas, 1991. Vol. IV, n. 7. p. 66-81.

ARIÈS, P; BÉJIN, A. (Org.). Sexualidades ocidentais. Contribuições para a história e para a sociologia da sexualidade. 2. ed. São Paulo: Brasiliense, 1986.

ARON, R. Mitos e homens. Rio de Janeiro: Fundo de Cultura, 1959.

BAKHTIN, M. Estética da criação verbal. São Paulo: Martins Fontes, 2003.

BRANDÃO, J. S. Dicionário mítico-etimológico da mitologia grega. 2. ed. Petrópolis: Vozes, 1993. Vol. I, p. 64-68, p. 544-548.

BRISSON, L. Sexual ambivalence. Androgyny and hermaphroditism in Graeco-Roman Antiquity. Trad. Janet Lloyd. Berkeley/ Los Angeles: University of California Press, 2002.

BURKERT, W. Mito e mitologia. Coimbra: Faculdade de Letras, 1986.

CASSIRER, E. A linguagem e o mito: sua posição na cultura humana. In:

Linguagem e mito. Uma contribuição ao problema dos nomes dos deuses. São Paulo: Perspectiva, 1972. p. 15-31.

COHEN, J. J. A cultura dos monstros: sete teses. In: SILVA, T. T. Pedagogia dos monstros. Os prazeres e perigos da confusão de fronteiras. Belo Horizonte: Autêntica, 2000. p. 23-60.

DELCOURT, M. Hermaphroditeetrites de la bissexualité dans l'Antiquité Classique. Paris: Les Belles Lettres, 1958. p. 29.

DOWDEN, K. Os usos da mitologia grega. São Paulo: Papirus, 1994.

ELIADE, M. História das crenças e das idéias religiosas. Tomo I: da Idade da Pedra aos Mistérios de Elêusis. Vol. I: das Origens ao Judaísmo. 2. ed. Rio de Janeiro: Jorge Zahar, 1983.

.Mefistófeles e o Andrógino. Comportamentos religiosos e valores espirituais não-europeus. 2. ed. São Paulo: Martins Fontes, 1999. p. 77-129.

ELIADE, M. Mito e realidade. Trad. Pola Civelli. São Paulo: Perspectiva, 2000.

FOUCAULT, M. História da sexualidade I. A vontade de saber. 13. ed. Trad. Maria Thereza da Costa Albuquerque e J. A. Guilhon Albuquerque. Rio de Janeiro: Graal, 1999.

Herculine Barbin dite Alexina B. Présentée par Michel Foucault. Paris: Gallimard, 1978.

. Herculine Barbin: o diário de um hermafrodita. Prefácio de Michel Foucault, novela de Oscar Panizza, trad. Irley Franco. Rio de Janeiro: Francisco Alves, 1982.

Os anormais. Curso no Collège de France (1974-1975). Trad. Eduardo Brandão. São Paulo: Martins Fontes, 2001.

FRIEDMAN, J. B. The monstrous races in medieval art and thought. London: Harvard University Press, 1981. p. 5-27.

FRYE, N. Anatomia da crítica. São Paulo: Cultrix, 1957. 
KAPPLER, C. Tipologia do monstro. In: . Monstros, demônios e encantamentos no fim da Idade Média. São Paulo: Companhia das Letras, 1993. p. 157-257. LEJEUNE, P. Le pacte autobiographique. Paris: Éditions du Seuil, 1975.

LIMC (Lexicon Iconographicum Mythologiae Classicae) Zurich: Artemis Verlag Zurich und Munchen, 1981. Vol. V, 5.

LUCIAN OF SAMOSATA. Dialogues of the Gods. English Translation by M.D. Macleod, London: Harward University Press, 1961. Vol. VII. p. 248-251; p. 322-323.

LUCRÉCIO. Da Natureza. Tradução e notas de Agostinho da Silva, estudos introdutórios de G. Ribbeck. São Paulo: Editora Globo, 1973.p. 31-143.

MÉNARD, R. A linguagem mitológica. A mitologia artística. As imagens dos deuses. In: MÉNARD, R. Mitologia greco-romana. Vol. I. São Paulo: Opus, 1997. p. 1-8.

MEYRINK, G. O Golem. São Paulo: Hermus, 2003.

NAZÁRIO, L. Da natureza dos monstros. São Paulo: Arte \& Ciência, 1998.

OVIDIO. Metamorfosi. Con un saggio di Italo Calvino. Torino: Einaudi, 1994.

. Salmácida, Hermafrodita. In: .As metamorfoses. Trad. David Gomes Jardim Júnior. Rio de Janeiro: Tecnoprint, 1983. p. 74-77.

PLATÃO; PLOTINO. O Banquete; Do amor. Trad. Albertino Pinheiro. Bauru: EDIPRO, 1996.

RICHEPIN, J. El Hermafroditismo. In Mitología clásica. 2. ed. México: UTEHA, 1951. Vol. I, p. 237-238.

SÓFOCLES. Antígona. Trad. Maria Helena da Rocha Pereira. Lisboa: Fundação Caloute Gulbenkian, 2007.

. Les Trachiniennes; Antígone. Texte Établi par Alphonse Dain et traduit par

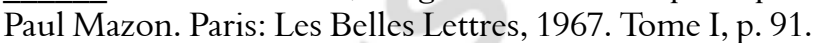

TEOFRASTO. Os caracteres. Texto estabelecido por Daisi Malhadas e Haiganuch Sarian. São Paulo: E.P.U., 1978. p. 89-96.

Charactères. Texte établie et traduit par Octave Navarre. Paris: Les Belles Lettres, 1964.

VERNANT, J. P. O universo, os deuses, os homens. São Paulo: Companhia. das Letras, 2000 . 